\title{
Mujeres Creando. El cuidado como maniobra ecológica de re-existencia.
}


MUJERES CREANDO.

CARE AS AN ECOLOGICAL RE-EXISTENCE MANEUVER.

\section{ABSTRACT}

This paper takes shape in the current socio-environmental context produced by the neoliberal hegemonic civilizational model, whose renewed extractivism perseveres in the dispossession and commodification of human and non-human life, subjecting social, economic, ecological and political relations to the logic of the more voracious capitalism. In the distribution of neoliberal restructuring, the tasks of caring for women throughout the planet have been essential, since they constitute one of the fundamental dimensions of the sustainability of life, that is, of social and ecosystemic reproduction.

In spite of this, these tasks have been ignored and excluded by the patriarchal, colonial and capitalist system through the invisibility of both the subjects that carry them out, and the ecological interrelationship and interdependence that characterize our relationship with the world. From this diagnosis, the Bolivian collective Mujeres Creando maneuvers a decolonial visuality, that comes from an always updated ancestral memory, through different artistic and cultural practices that restore care in the center.

Both to face the neo-extractive system that is presented as the panacea of development and modernization in the countries of the South, and for the claim and achievement of a series of human rights and citizenship.

\section{Keywords}

Mujeres Creando; care; ecological maneuvers; re-existence; decolonial visualities. 


\section{MUJERES CREANDO. \\ EL CUIDADO COMO MANIOBRA ECOLÓGICA DE RE- EXISTENCIA.}

\section{RESUMEN}

El presente artículo toma cuerpo en el contexto socioambiental actual producido por el modelo civilizatorio hegemónico neoliberal, cuyo renovado extractivismo persevera en el despojo y la mercantilización de la vida humana y no humana, sometiendo las relaciones sociales, económicas, ecológicas y políticas a la lógica del capitalismo más voraz. En el reparto de las reestructuraciones neoliberales, las tareas de cuidado de las mujeres en todo el planeta han sido imprescindibles, puesto que, constituyen una de las dimensiones fundamentales de la sostenibilidad de la vida, es decir, de la reproducción social y ecosistémica.

A pesar de ello, estas tareas han sido ignoradas y excluidas por el propio sistema patriarcal, colonial y capitalista mediante la invisibilización tanto de los sujetos que las realizan como de la interrelación e interdependencia ecológicas que caracterizan nuestra relación con el mundo. Desde este diagnóstico, el colectivo boliviano Mujeres Creando maniobra una visualidad descolonial, que proviene de una memoria ancestral siempre reactualizada, por medio de diferentes prácticas artísticas y culturales que reponen el cuidado en el centro.

Tanto para enfrentarse al sistemaneoextractivista que se presenta como la panacea del desarrollo y la modernización en los países del Sur como para la reivindicación y consecución de una serie de derechos humanos y de ciudadanía.

\section{Palabras Clave}

Mujeres Creando; cuidado; maniobras ecológicas; re-existencia; visualidades descoloniales. 


\section{INTRODUCCIÓN}

El presente artículo toma cuerpo en el contexto socioambiental actual producido por el modelo civilizatorio hegemónico neoliberal, cuyo renovado extractivismo persevera en el despojo y la mercantilización de la vida humana y no humana, sometiendo las relaciones sociales, económicas, ecológicas y políticas, a la lógica del capitalismo más voraz. La instalación de megaproyectos extractivos implica la rasgadura de los lazos comunitarios, la pérdida de las economías regionales y la merma de la diversidad naturocultural. Así, los territorios donde se establecen son fragmentados y desarticulados de las relaciones locales, para ser insertados en las cadenas globalizadas de las grandes corporaciones.

En este sentido, Bolivia ha sido históricamente uno de los lugares más afectados de América Latina. En la actualidad, a pesar de las profundas transformaciones políticas conseguidas por el arduo e incansable trabajo de los movimientos sociales, el saqueo y la explotación persiste sobre sus territorios y habitantes en una continuación del modelo imperial. Una de las causas, como explica Julieta Paredes, ha sido el colonialismo interno ${ }^{1}$ que, "además de nutrir económicamente las arcas transnacionales con mano de obra barata de jóvenes hombres y mujeres indígenas, ha subvencionado sus mesas cotidianas con el bajo costo de los productos agrícolas procedentes del trabajo de las comunidades rurales" (Paredes, 2014 [2008], p.15). Un sistema de organización social misógino católico y colonialista, como ella lo califica, que hace que la explotación laboral más brutal recaiga sobre las mujeres de los pueblos marginados, tanto en el ámbito de la sociedad blanca-mestiza, como al interior de las comunidades indígenas. En sintonía, Silvia Rivera Cusicanqui expresaba:

(...) en la contemporaneidad boliviana opera, en forma subyacente, un modo de dominación sustentado en un horizonte colonial de larga duración, al cual se han articulado, pero sin superarlo ni modificarlo completamente, los ciclos más recientes del liberalismo y el populismo. Estos horizontes recientes han conseguido tan sólo refuncionalizar las estructuras coloniales de larga duración, convirtiéndolas en modalidades de colonialismo interno que continúan siendo cruciales a la hora de explicar la estratificación de la sociedad boliviana y los mecanismos específicos de constitución identitaria en el ámbito político. (Rivera, 2010, pp. 36-38)

En el reparto de las reestructuraciones neoliberales, las tareas de cuidado de las mujeres en todo el planeta han sido imprescindibles, pues si a partir de la colonia fueron incorporadas a la matriz productiva, en la actualidad son motor multifunción como parche y mano de obra barata, y como cuidadoras y sostenedoras de la vida de toda la familia. Las tareas de cuidado son imprescindibles para vivir desde que nacemos hasta que morimos. Por ello, constituyen una de las dimensiones fundamentales de la sostenibilidad de la vida, es decir, de la reproducción

\footnotetext{
1 El "colonialismo interno" es un concepto desarrollado por Pablo González Casanova para explicar cómo tras la independencia de los Estados coloniales, "los pueblos, minorías o naciones colonizados por [los nuevos] Estado-nación sufren condiciones semejantes a las que los caracterizan en el colonialismo y el neocolonialismo a nivel internacional: habitan en un territorio sin gobierno propio; se encuentran en situación de desigualdad frente a las elites de las etnias dominantes y de las clases que las integran; su administración y responsabilidad jurídico-política conciernen a las etnias dominantes, a las burguesías y oligarquías del gobierno central o a los aliados y subordinados del mismo; sus habitantes no participan en los más altos cargos políticos y militares del gobierno central, salvo en condición de "asimilados"; los derechos de sus habitantes y su situación económica, política, social y cultural son regulados e impuestos por el gobierno central; en general, los colonizados en el interior de un Estado-nación pertenecen a una "raza" distinta a la que domina en el gobierno nacional, que es considerada "inferior" o, a lo sumo, es convertida en un símbolo "liberador" que forma parte de la demagogia estatal; la mayoría de los colonizados pertenece a una cultura distinta y habla una lengua distinta de la "nacional" (González Casanova, 2003, p.3)...
} 
social y ecosistémica. Sin embargo, estas tareas han sido ignoradas y excluidas por el propio sistema patriarcal, colonial y capitalista, mediante la invisibilización tanto de los sujetos que las realizan como de las ideas de interrelación e interdependencia que caracterizan nuestra relación con el mundo.

Frente a este horizonte, nuestra propuesta es entender el cuidado, no solo como un concepto potente, sino como una práctica política de re-existencia ${ }^{2}$ que puede ser ejercida estratégicamente contra el despojo y en defensa de la vida. Tanto para enfrentarse al sistema neoextractivista que se presenta como la panacea del desarrollo y la modernización en los países del Sur, como para la reivindicación y consecución de una serie de derechos humanos y de ciudadanía, de la mano de trabajadoras precarias que desempeñan un trabajo vital, en tanto que "trabajo vivo", ya sea en zonas rurales o urbanas de todo el planeta.

Ahora bien, los trabajos de cuidados no pueden ser aprehendidos de la misma manera en ámbitos geo-corpo-políticos distintos. En Bolivia, como en otros lugares de América Latina, la cosmovisión andina sigue presente en sus prácticas cotidianas y complejizan la noción de cuidado al poner especial empeño en una relación integral con la naturaleza, entendida como un espacio vital que no puede escindirse del mundo social. Por lo que la idea de interdependencia y cuidado humano se extendería también al cuidado de los "bienes comunes" de la naturaleza.

Estas prácticas locales de lo socionatural son el punto de partida de las luchas del movimiento de pueblos y nacionalidades originarias indígenas, del movimiento de mujeres y el movimiento ambiental en todo el mundo, y han de ser entendidas como "luchas por la defensa de la diferencia cultural, económica y ecológica” (Escobar, 2003, p.78).

Desde este diagnóstico, el colectivo boliviano Mujeres Creando maniobra una visualidad descolonial por medio de diferentes prácticas artísticas y culturales que re-ponen ${ }^{3}$ el cuidado en el centro. Tanto para enfrentarse al sistema neoextractivista que se presenta como la panacea del desarrollo y la modernización en los países del Sur, como para la reivindicación y consecución de una serie de derechos humanos y de ciudadanía. Cuidado y afectos abastecidos primordialmente por la creatividad o inventiva individual, comunitaria y familiar, que provienen de una memoria ancestral, siempre reactualizada, sin las cuales estas entidades no existirían.

Todas ellas son nudos de un entramado que formula otras maneras de ver, cuyas aportaciones radican en el deseo compartido de transformar el cuidado en una herramienta política capaz de articular una responsabilidad en el sostenimiento de la vida que sea colectiva, desfeminizada y visible. Tales maniobras nos interesan, en tanto que su defensa del lugar se convierte en una política del lugar, es decir:

2 La noción de "condiciones de la re-existencia" (más allá de la resistencia) fue propuesta por Adolfo Albán Achinte en el contexto de la reunión llevada a cabo en Caracas, en mayo de 2007, por el grupo Modernidad/Colonialidad/Decolonialidad, donde se debatió -entre otros asuntos- la cuestión de visionar los tipos de sociedades descoloniales que podrían desear construir (Escobar, 2010 [2008], p.351). Albán se refiere a ella como prácticas mediante las cuales las comunidades recrean sus mundos materiales y simbólicos, y desde allí se enfrentan a las desigualdades, la marginalización, la discriminación y la racialización (Adolfo Albán, 2013). 3 Como explican Precarias a la deriva, más que "poner", se trata de re-poner, "porque el cuidado, tal y como lo entendemos, ya está, de hecho, en el centro. Aún más: siempre ha sido y continúa siendo, hoy más que nunca, el centro. El centro en el sentido de principio y principal, como arché de la existencia humana y de las relaciones sociales" (Precarias a la deriva, 2005).. 
Cuando las mujeres subalternas se involucran en luchas políticas colectivas referidas al lugar, vinculando voces subalternas con la acción colectiva en contra de la desigualdad. Además, entre estas últimas escogeríamos centrarnos en la política del lugar transformadora y no en las defensas reaccionarias del status quo por parte de los grupos subalternos. Esta política transformadora puede incluir resistencia, pero también reapropiación, reconstrucción, reinvención, incluso la relocalización de lugares y prácticas basadas en lugares y la creación de nuevas posibilidades de estar en un lugar y estar en redes con otros seres vivos, humanos y no humanos. (Escobar y Harcourt, 2005, p.13)

\section{MANIOBRAS ECOLÓGICAS Y VISUALIDADES DESCOLONIALES}

El concepto de maniobra que llevo utilizando durante años en mis investigaciones es una metáfora que tiene su origen en el contexto latinoamericano. Concretamente, es usado en los años noventa por feministas chicanas como, Gloria Anzaldua, Cherri Moraga, Norma Alarcón o Chela Sandoval. Esta última, se refiere a él en su obra Metodology of Opressed (2000), para aludir a un tipo de prácticas revolucionarias, de movidas hacia la descolonización del ser (p.140).

Si atendemos a la etimología del término, "maniobra" tiene dos componentes léxicos, "mano" y "obra", y significa "operación, manejo", hacer cosas con las manos. Las feministas chicanas vieron en este término una metáfora transformadora para explicar la potencia material del cuerpo y de las subjetividades comprometidas con lo político. Pero, además, el sentido de movidas al que alude Sandoval nos hace pensar en movimientos $y$, por ende, en transformaciones, así como en herramientas o vehículos que podemos utilizar para maniobrar/desviar la producción del sentido común.

En mi caso, desde el ámbito de mi formación en Historia del arte, pienso en prácticas artísticas y culturales que se constituyen como un procedimiento material, un modo activo de provocar cambios en la producción de la visualidad hegemónica manejando visualidades alternativas, descoloniales, que cuestionan y desmontan ese régimen de sentido que fomenta y perpetúa jerarquías de clase, étnicas, sexuales, geopolíticas y de género. A partir de aquí, lo que hago es zurcir códigos, conectar maniobras con ecología (en alusión a la "ecología de saberes" que propone Boaventura de Sousa Santos (2006), como mi estratégica movida, para aludir a aquellas prácticas artísticas y culturales capaces de transformar y mitigar la persistencia de la colonialidad de la mirada, mediante una redistribución de las relaciones de poder y de las formas de conocimiento dominantes con la finalidad última de sostener la vida.

Como dice Sandoval, las maniobras utilizadas de forma conjunta crean "historias embusteras, estratagemas de magia, decepción y verdad para curar el mundo" (Sandoval, 2004 [1995], p.87). Curar también significa cuidar. En su origen expresaba una actitud de atención y sentido de responsabilidad, pero, además, de pensar, de pensar en el otro, de responsabilizarse de sus necesidades. 
A este bastidor cuyo marco es el cuidado de la vida humana y no humana, se incorporan las fibras que conforman el "tejido de la rebeldía" (Guzmán y Paredes, 2014 [2008]), la "alianza entre rebeldes" (Galindo, 2005) de Mujeres Creando (MC). Un grupo activista boliviano que surge en La Paz en 1992, de la mano de la entonces pareja afectivo-intelectual formada por María Galindo (de origen mestizo) y Julieta Paredes (de origen aymara), a las que se uniría Mónica Mendoza. Este grupo de vocación e intuición feminista anarquista ofrecía en aquellos años una propuesta éticopolítica concreta que sobrepasaba los límites de la crítica de la izquierda al neoliberalismo. Proponía un proyecto político integral de descolonización atravesado por el eje de la despatriarcalización, ya que, consideraban el patriarcado como el sistema de todas las opresiones de todo lo que vive en el planeta, "hombres, mujeres, personas intersexuales, y la naturaleza" (Paredes, 2013). Esta premisa continua hasta la actualidad en sus idearios y prácticas a pesar de que el grupo se disolvió en el año 2002, dando lugar a otras dos formaciones, comunidad Mujeres Creando comunidad (fundada por Julieta Paredes) y Mujeres Creando (concebida por María Galindo). ${ }^{4}$

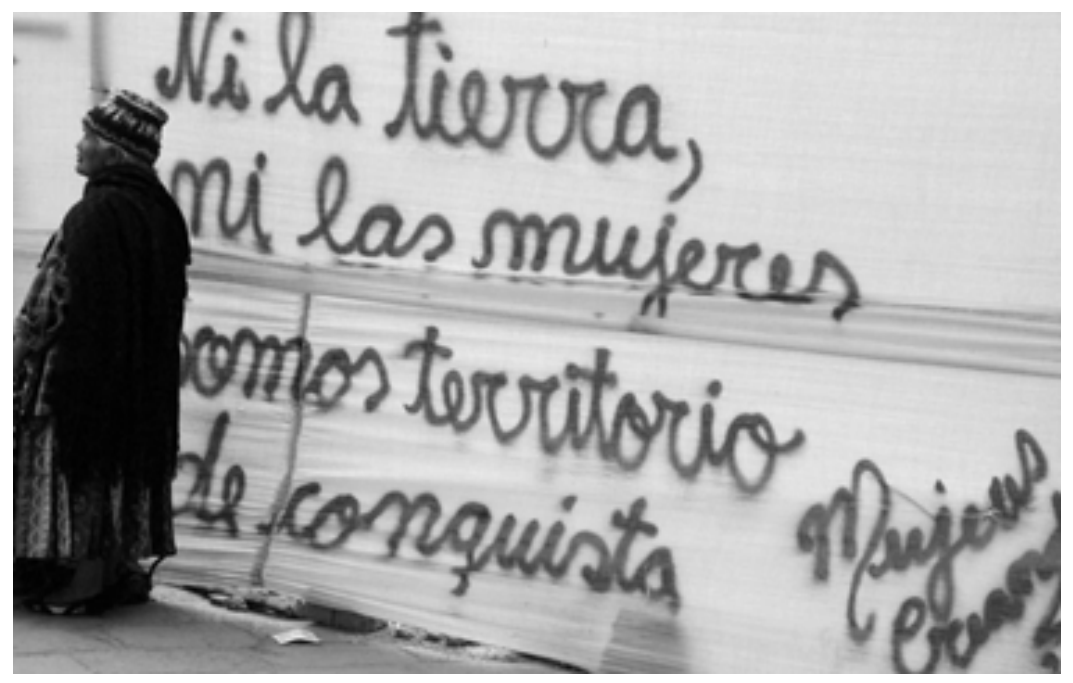

Figura 1. Mujeres Creando. Grafiteada, La Paz, Bolivia.

(Fuente:https://www.elconfidencial.com/cultura/2015-02-23/mujeres-creando-20-anos-contra-la-autoridad_715427/)

4 Es por ello que en este artículo solo se alude al trabajo realizado por el movimiento en los años noventa, puesto que, tras su disolución, existen diferencias en los dos nuevos colectivos creados que requeriría de un análisis por separado. 
Desde sus inicios, MC localizó sus prácticas en dinámicas de barrio y comunitarias, especialmente en el contexto urbano paceño, si bien, sus intereses y acciones también abarcaron zonas y comunidades rurales. Sus alicientes partían del derecho a hablar con voz propia y a agenciar su propia imagen, todavía usurpadas por el neoliberalismo, el colonialismo interno, el patriarcado reciclado y el feminismo hegemónico. La idea de crear comunidad se había materializado en una casa en el barrio de las Delicias, en la que convivían junto a mujeres de la ciudad y del campo, mestizas, aymaras y quechuas, universitarias, amas de casa, madres solteras, lesbianas, etcétera. Construida por muchas manos, pronto crearon la Despensa de la Abuela, donde se dispensaban alimentos naturales para el barrio; el Panal de las Abejitas, biblioteca y lugar pedagógico para niños y niñas (Guzmán y Paredes, 2014, p.50); así como talleres de salud y de alfabetización de un grupo de estudiantes de Achacachi. Este primer espacio comunitario abrió el camino en 1992 al Café Carcajada, centro cultural feminista, heterogéneo, autónomo y autogestionario desde el que "complotar" contra el poder patriarcal.

De este modo, fueron poco a poco no solo construyéndose un pensamiento propio, sino también una metodología propia que les permitiría llegar a la gente "normalita" en su cotidianeidad. Por lo que comenzaron una serie de movidas estético-políticas basadas en los principios de horizontalidad y complementariedad que no buscaban el protagonismo del "artista-genio", sino que, por el contrario, trataban de desacralizarlo. ${ }^{5}$ La violenta supresión histórica de las mujeres bolivianas les confería la fuerza y la inventiva necesaria para disputarle al sistema el espacio físico y simbólico arrebatado. Apropiación de la que depende su existencia, por eso resulta vital. Este reconocimiento de la otra existencia, de la alteridad, como real y no como ficción, es lo que, según J. Paredes, permite visibilizar a las mujeres invisibilizadas (Paredes, 2014 [2008], p.34). Es decir, la demanda no es ser representadas, sino reconocidas socioculturamente, hacerse ciudadanamente visibles en su diferencia.

Este marco interpretativo-metodológico está basado en la coexistencia conflictiva de "dos horizontes de memoria" colectiva y pertenencia ideológica: la memoria larga y la memoria corta. Siguiendo el argumentario de Silvia Rivera Cusicanqui en Violencias (re)encubiertas en Bolivia (2010), la primera es aquella memoria que mantiene la conciencia de opresión colonial de más de quinientos años que permanece sobre las sociedades indígenas y que despierta la potencia de poner en marcha procesos que desarticulen esta condición histórica de subalternidad. Al tiempo, que va reformulando las fronteras de las memorias cortas colectivas que son de menor trayecto temporal, marcadas por el neoliberalismo, propias de horizontes históricos que se van superponiendo, encontrando y antagonizando.

Desde esta lectura, la memoria que en nuestra conceptualización occidental ahora denominamos ecológica, es decir, el pasado que se mantiene, al menos en parte, cifrado y guardado en la estructura y funcionamiento de los ecosistemas y de los paisajes, que, persiste de manera subyacente, y puede expresarse o activarse en un futuro, pero también, perdura en los procesos activos que se originaron en el pasado y se proyectan hacia el futuro- es la memoria ancestral de los pueblos originarios, siempre renovada, que se funda en un profundo respeto y reconocimiento de la integralidad de la existencia, que pasa por la experiencia del cuidado de la vida humana y no-humana. La reciprocidad, complementariedad, vincularidad y correspondencia respecto a la Madre Tierra, a la Pachamama, son principios de la cosmovisión

5 En el caso de las grafiteadas, por ejemplo, M. Galindo se expresa diciendo: "nosotras entendemos las pintadas como una acción artística y por eso reconocemos la autoría solo cuando extractamos un verso escrito, porque su fuerza incontenible no es la individualidad sino la colectividad, pensante, actuante, y soñante". (Galindo y Paredes, 1999, p.19) 
andina, también de otras cosmovisiones amerindias, que se reactualizan constantemente. En este sentido, Javier Lajo explica que "existe una vigente 'aspiración' de re-equilibrar el mundo a partir del equilibrio de la pareja humana, comunidad-sociedad, y la naturaleza”. Una memoria viva que encamina sus luchas ontológicas y epistemológicas para construir un sentido común emancipador.

Sobre esta base, la creatividad e imaginación política significada en sus grafiteadas, publicaciones y performances, se erige en herramienta de lucha clave para desneoliberalizar, descolonizar y despatriarcalizar el aparato de producción de imaginario que las ha subyugado históricamente, mediante un trabajo, un recorrido y una experiencia contiguos a la comunidad. Pues a través de ellas consiguen desarmar toda una maquinaria de sentidos visuales, infiltrándose en el entramado social y logrando la comunicación. ${ }^{6}$ Con ellas "siguen instalándose en los corazones de las desprevenidas y desprevenidos, llamando a la desobediencia, al placer, al amor, a la lucha a ser parte de nuestra vida cotidiana" (Galindo y Paredes, 1999, p.17).

En el caso de las grafiteadas (mezcla de grafiti y pintada) (Galindo y Paredes, 1999, p.11), se trata de una óptica propia en las que el color, las formas, las consignas, y el lenguaje poético se articulan para la transformación social. Si bien poseían un bagaje en pintadas durante su activismo en la izquierda, las grafiteadas dieron un giro a las mismas: buscaban desbaratar el lenguaje repetitivo, machista y homofóbico que las caracterizaba, para embellecer las paredes de la ciudad con sarcasmo, humor, sagacidad y poesía.

Porque para nosotras el arte que no se compromete con la vida, no embellece la vida, solo la maquilla, la remienda o la decora, y lo que nosotras buscamos, con nuestro arte es embellecer la vida, la vida de cada día, dar ánimo y solidaridad a las mujeres que luchan contra el machismo, cuestionar a los varones en su complicidad con el sistema patriarcal, hacer reflexionar a las mujeres sobre temas que nos dan miedo como las dictaduras y la historia, apoyar a los varones que luchan contra el fascismo y las dictaduras, que cada loca y loco que cree en el amor, la justicia y la libertad no se sienta solo, que lea y nos sienta sus hermanas. (Galindo y Paredes, 1999, pp. 12-13)

Esta idea de embellecer no se deriva de la estética occidental, sino que obedece a una trayectoria diferente y confronta los patrones de poder del arte hegemónico. Se propone como parte de una cosmovisión, de una opción de vida que persigue el Vivir Bien, la alegría, el placer, la justicia social y la solidaridad en la comunidad de comunidades. Inciden en una desvinculación de las estructuras canónicas, de sus genealogías artísticas, de sus dispositivos creativos con sus patrones y límites reduccionistas, clasistas y racistas, para sumergirse en el amplio mundo de lo sensible, donde la mujer, como ser autobiográfico, recupera y escribe su propia historia. Esto pasa por situar la episteme sobre el cuerpo y significarlo para el accionar político a partir de sus experiencias fraguadas en situaciones de marginalización, subyugación, explotación y muerte. No se trata de un cuerpo heroico ni militarizado, sino "vulnerable, sensible, sensual, creativo, desarmado y no violento" (Galindo y Paredes, 1999, p.23), que actúa en una variedad de situaciones, relaciones y escenarios de vida.

6 A este respecto explica J. Paredes, "el sistema patriarcal es bien mañudo y como lo dijimos antes se recicla, comiéndose los sueños y las estrategias de lucha de nuestros pueblos. Si bien inventamos palabras, formas o cosas, ya nomas rápido lo cooptan, lo manipulan, lo copian. [...] La creatividad es un instrumento de lucha que nos permite siempre escapar de la cooptación, del uso y la manipulación, es un instrumento que permanentemente se renueva y siempre se está moviendo. Como siempre estamos creando algo nuevo, entonces es más difícil agarrarnos, es más difícil que nos puedan desmenuzar y digerir. (Guzmán y Paredes, 2014, p.99) 




Figura 2. Mujeres Creando. Grafiteada, La Paz, Bolivia.

(Fuente:https://es.wikipedia.org/wiki/Mujeres_Creando\#/media/Archivo:Pintada_en_La_Paz_de_Mujeres_ Creando_2017_-_2.jpg)

Uno de esos escenarios es la calle. Espacio entendido como "campo vital" donde el cuerpo se desarrolla. Donde sus paredes, "las pizarras del pueblo", cumplen el papel de la información (Paredes, 2014 [2008], p.40). Pues como sugiere M. Galindo, "si las paredes hablaran pedirían grafitis para tener boca y brazos para hablar y abrazar" (Galindo y Paredes, 1999, p.16).

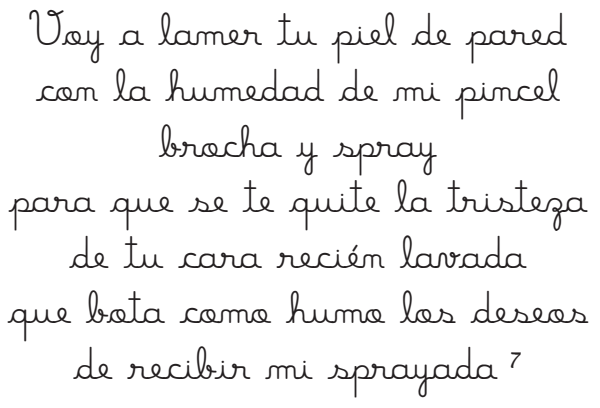

A este respecto, la tipografía cumple, junto al lenguaje poético, un cometido fundamental, ya que, convierte la idea verbal en forma visual, planteando legibilidad en el mensaje y fuerza en el concepto a transmitir. De modo que, se compone un dispositivo que conjuga la cercanía fonética, la articulación semántica y la imagen visual. Ciertamente, la elección de una tipografía caligráfica, que emula una escritura manual sencilla y reconocible, fortalece la intención comunicativa. Después de todo, su finalidad es concientizar, convocar y seducir a la gente mediante una semántica-gráfica espontánea y popular, que marca una distancia con el tono elitista propio de la vanguardia del arte que tiende a operar dentro del sistema semiótico dominante. 
Para MC, "la forma expresa el contenido y el contenido a su vez crea las formas", pues es un proceso de cuestionamiento de las mismas, de creación, recreación y a la vez de coherencia ética (Galindo y Paredes, 1999, p.2).

La elección de esta forma de comunicación es coherente con su manera de concebir las relaciones. El grafiti expresa colectivamente lo que colectivamente se quiere expresar: la crítica de la vida cotidiana, del sentimiento compartido de los problemas que aquejan a la mayoría. Interpelan a la sociedad y en especial a las mujeres a partir de la convicción de que la posibilidad de cambiar las cosas reside en la reciprocidad y la solidaridad. Resquebrajan, así, el individualismo y la imposibilidad de cambiar las estructuras sostenidos por el énfasis en la macroeconomía y la capitalización de los distintos gobiernos de los años noventa, que reforzaron el proyecto neoliberal como forma naturalizada de práctica económica y política.

A partir de esta grafía se persigue que las mujeres recobren la decisión existencial sobre sus propias vidas, y no olviden que el aparato simbólico continua persistentemente su embate, pues "es sobre los hombros de las incorporadas al mercado laboral en condiciones desiguales, las que salvamos la economía en sus diferentes crisis y sostenemos la sobrevivencia y la vida, tanto de las personas, las familias, como de nuestro planeta", que continúa recayendo la responsabilidad última (Paredes, 2013). De ahí su llamada a la desobediencia mediante una desobediencia visual, que encontró y sigue encontrando en las paredes paceñas "la complicidad para decir lo que no se debía" (Guzmán y Paredes, 2014, p.51).

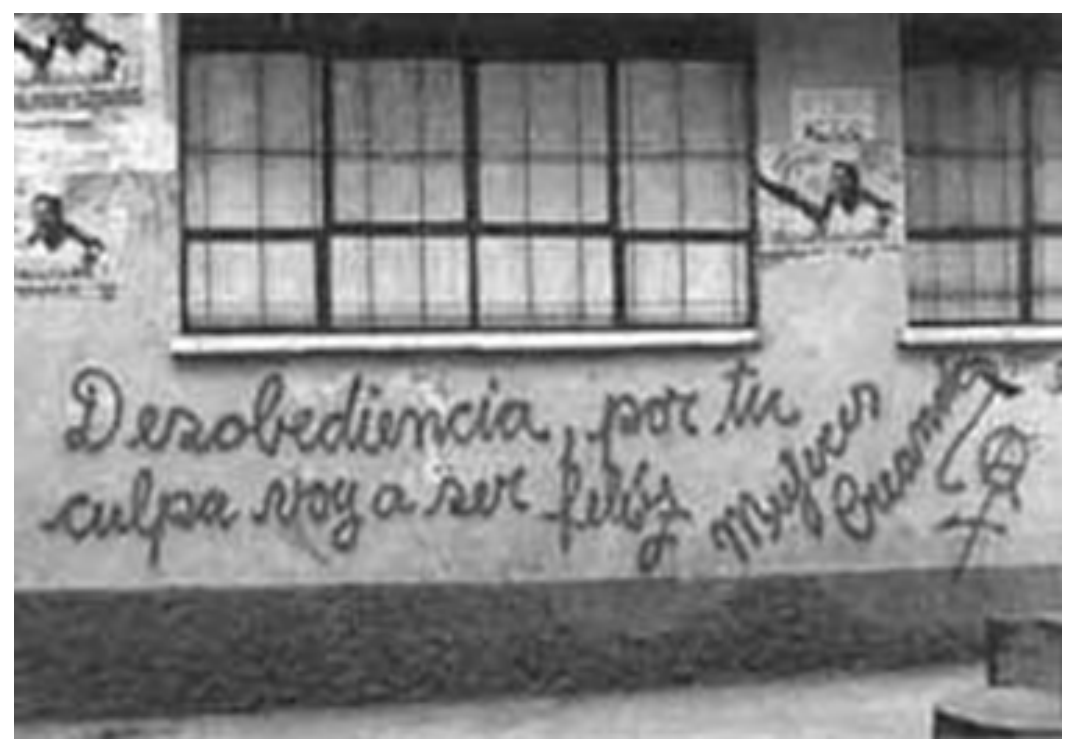

Figura 3. Mujeres Creando. Grafiteada, La Paz, Bolivia. (Fuente: http://mujerescreandocomunidad.blogspot.com) 
Si bien, las grafiteadas no guardan un orden temático, puesto que encierran en sí mismas la crítica a una complejidad de opresiones, muchas de ellas interpelan con fuerza el rol de la mujer como cuidadora que ha de sacrificarse por las vidas de los demás, tanto a nivel material, como afectivo, olvidándose de la suya propia. De modo que, los cuerpos y las paredes puestos a trabajar en común son las superficies donde se inscriben estas relaciones de poder, pero, también, el lugar de la libertad, pudiendo observar en ellas un cultivo fértil de "micro-rebeldías" (Guzmán y Paredes, 2014, p.151).

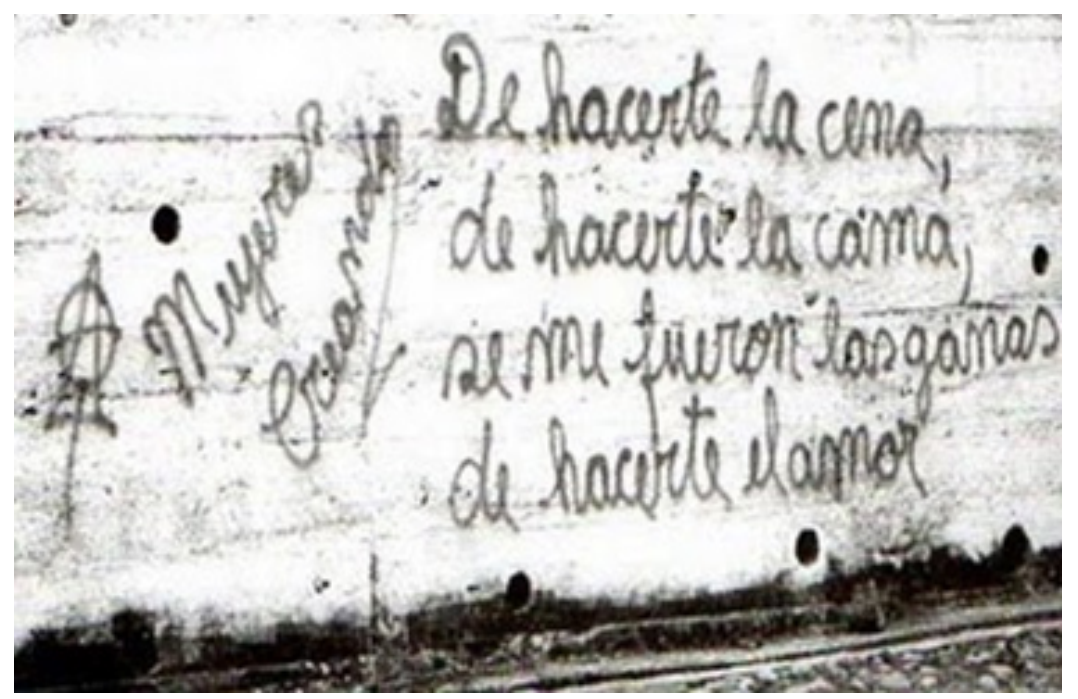

Figura 4. Mujeres Creando. 1999. Grafiteada, La Paz, Bolivia.

(Fuente: https://www.escritosenlacalle.com/detalle_grafiti.php?Grafiti=419)

Las grafiteadas suponen un proceso de reflexión colectiva sobre la calle, la ciudad, el espacio, y el tiempo histórico político de las mujeres. Enunciaciones emancipatorias que se configuran frente a los nuevos carices que van tomando las diversas formas en que se expresa el poder neoliberal, estatal y patriarcal. Si este persiste en invisibilizar a las mujeres, confinando material, imaginaria y simbólicamente sus cuerpos, trabajos y conocimientos de cuidados con los que desarrollar una economía de existencia, MC disputa la calle y contiende la ciudad para convertirla no solo en un espacio doméstico, sino también, en un tiempo doméstico y cotidiano.

Esta reflexión sobre el tiempo resulta vital, pues como explica Julieta Paredes, de acuerdo con la lógica patriarcal las mujeres viven un tiempo "no importante", frente al tiempo importante de los hombres. Es marcado como tal por entender que las mujeres realizan tareas de segunda, triviales e insignificantes, a pesar de que, es un tiempo durante el que se realizan tareas imprescindibles e importantes para la vida, necesarias para cuidar la vida de los otros cotidianamente: 
Las consecuencias de estas lógicas de pensamiento se ven en la alienación completa de las mujeres, en tareas tediosas y repetitivas de la cotidianeidad como el lavar, cocinar, cuidar las wawas. El espacio está ahí lo podemos ver y tocar, pero el tiempo se nos esfuma de los cuerpos y las manos. [...] En la dimensión de la categoría tiempo, se comprende el concepto de cotidianeidad como un movimiento cíclico sin el cual la vida no podría subsistir, es cíclico y repetido, pero no por eso puede suponerse que deba ser aburrido y con falta de creatividad en sí, [...] pero lo cierto es que al ser carga horaria sin reconocimiento ni valoración productiva en las espaldas de las mujeres, se convierte en una condena gratuita y diaria. Se suele anteponer, desde la lógica patriarcal, lo cotidiano, como lo secundario, aburrido y sin trascendencia, entonces se le asigna a la mujer. En vez, lo histórico es considerado lo trascendente e importante, entonces se le asigna al varón. En nuestra concepción, la cotidianeidad y lo llamado histórico son un continuum, son parte de la vida que se alimenta. (Paredes, 2014 [2008], p.44)

En las distintas grafiteadas vemos plasmado que el carácter subversivo y la rebeldía se proponen desde el propio espacio doméstico y cotidiano, como en "No lo dejes para mañana si puedes dejarlo hoy", donde la riqueza poética se desborda en la parodia de un refrán castellano que impele a ser diligentes con el trabajo pendiente. La ironía tiene como eje central el tiempo, en el que se anima a las mujeres a dejar a los maridos machistas para recuperar el tiempo perdido.

Las grafiteadas inauguraron dinámicas intersubjetivas, encuentros, negociaciones y acciones políticas que encontraron en los medios de comunicación el vehículo para seguir creciendo. Por ello, en 1995, MC inició la publicación de la revista Mujer Pública. En esta se deliberaba sobre el ideario de la comunidad y sus propuestas de vida desde una posición crítica que incluía el propio auto-cuestionamiento, así como todos aquellos pormenores y "pormayores" de la vida cotidiana de las mujeres. La financiación se llevaba a cabo mediante su venta, la cual se realizaba por ellas mismas en las calles y en las plazas de la ciudad. Este hecho les garantizaba su independencia, al tiempo que las invitaba a poner en práctica ejercicios de imaginación e inventiva con el fin de atraer a los viandantes y convencerlos para su compra. Dichos ejercicios han sido considerados como el germen de sus acciones callejeras, a dos de las cuales nos vamos a referir a continuación, Acción 2 y Acción $8^{8}$. Acciones que no son consideradas por MC como teatro ni show, sino que, por el contrario, son puestas en práctica como acciones sencillas y cotidianas con las que hacer política desde la calle. Sendas fueron realizadas en plazas públicas de La Paz, en el contexto de los años noventa, de las cuales se generaron a posteriori diversos documentos audiovisuales. ${ }^{9}$

La primera acción a la que aludimos consistió en llevar a cabo una comida comunitaria en un espacio público concurrido de la ciudad, en la que los alimentos eran compartidos con los viandantes. Para ello, sobre un lecho de plantas montaron una gran mesa sobre la que fueron acomodando viandas, frutas y papas, al tiempo que las mujeres y las wawas danzando en círculo cogidas de las manos, o tumbadas en el suelo boca arriba alrededor de la misma, exhibían sus pancartas, cuya consigna principal era la palabra "Utopía". Los cantos de Julieta y las danzas de

\footnotetext{
8 Disponibles en: http://hemisphericinstitute.org/hemi/es/modules/itemlist/category/237-mujeres-works.

9 Algunos especialistas sugieren que el video de un performance no es el performance, no es la presencia en vivo efímera, sino el registro del archivo (Taylor, 2011, p.22). De tal forma que, estaríamos ante un formato audiovisual que, a través de sus posibilidades creativas de montaje y edición, lo que documenta e intenta preservar construye y crea algo nuevo. En cualquier caso, para nuestro análisis resultan interesantes estos videos tanto por la difusión de la memoria cultural que ofrecen, como por el modo en que le dan forma a la subjetividad, a la expresión artística, a la vida cotidiana y al cuerpo en sí mismo.
} 
María evidenciaban el carácter festivo y lúdico que invitaba explícitamente a los ciudadanos de a pie a participar. Queremos hacer notar que el vídeo comienza con la acción de Julieta estrellando un televisor contra el suelo. A partir de aquí, la cámara se acerca al mismo hasta hacer un fundido en negro, para reaparecer inmediatamente después la imagen de su acción callejera.

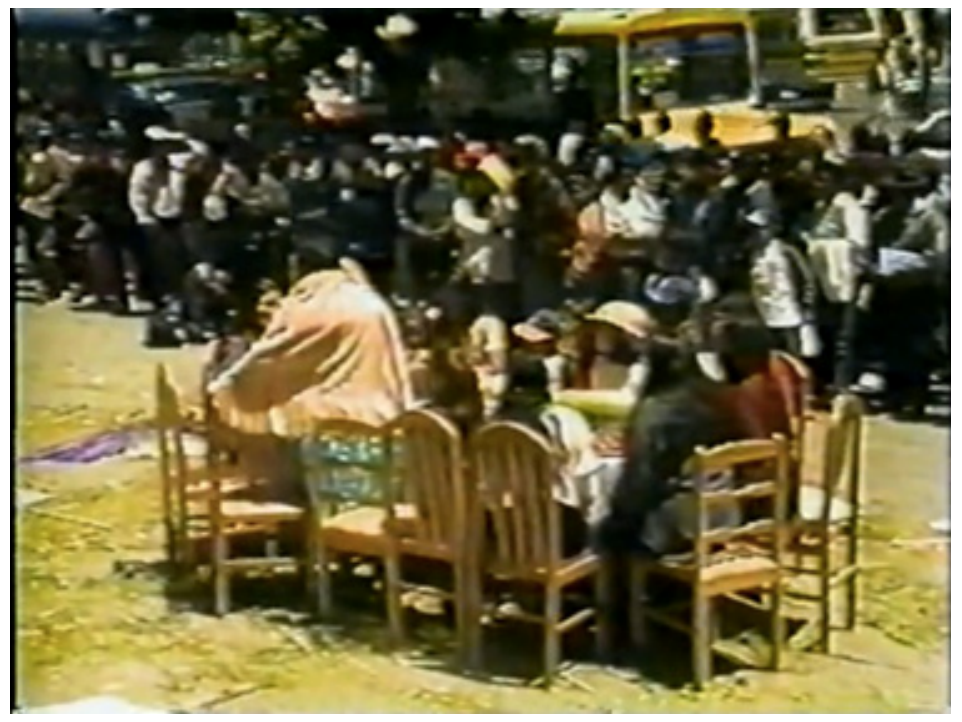

Figura 5. Mujeres Creando. Acción 2, 1992. Videoperformance, La Paz, Bolivia.

(Fuente: http://hemisphericinstitute.org/hemi/es/modules/itemlist/category/237-mujeres-works)

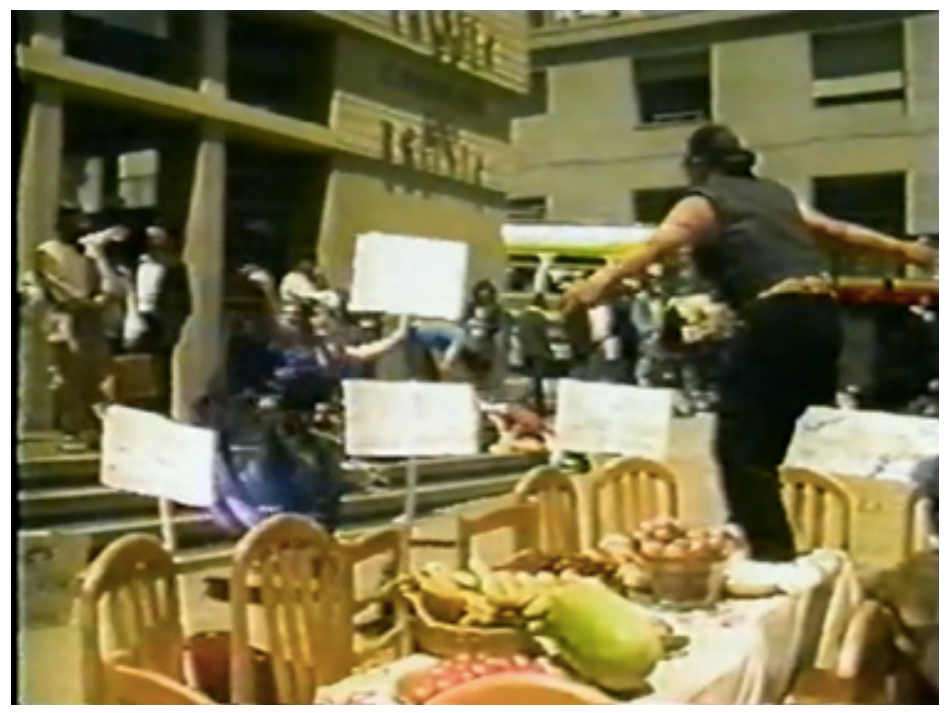

Figura 6. Mujeres Creando. Acción 2, 1992. Videoperformance, La Paz, Bolivia. 
Desde la experiencia doméstica de preparar la comida en la calle, a la luz del día, de poner la mesa, de alimentar a las wawas, que habitualmente se ejerce en la intimidad de las cocinas y las casas, se pretendía un reconocimiento al sostén y al cuidado de la familia que ejercen las mujeres en la procuración diaria de alimentos, al tiempo que reclamaban un reconocimiento recíproco que tiene como base el derecho humano a la alimentación, a la seguridad alimentaria. Este derecho parece ser entendido como utópico por la sociedad actual, pues el neoliberalismo nos ha hecho ver como natural que una parte de la población mundial haya de vivir en situación de pobreza extrema y escasez alimentaria, llegando incluso a la muerte. Como también se han naturalizado la opresión y la discriminación que sufren las mujeres en cuanto a las labores de cuidado. De ahí que en las pancartas se podían leer consignas como: "La utopía es pobre y amenaza tus privilegios", "La utopía es sorda y habla a gritos", "La utopía es estridente, es intransigente", "La utopía es rubia y morena al mismo tiempo". Enunciados que se coreaban con las voces de María y de las otras mujeres:

La utopía es rebelde, desobediente, se parte, se reparte, todas la compartimos, porque es un pedazo de amor igual que la comida, no tiene edades, es vieja como nuestro dichos, pero también es niña, una niña pequeñita que tiene miedo, que tiene sueños y necesidades que exigen luchar por nuestras wawas, para que tengan comida, para que tengan escuelas, para que tengan salud, para que tengan todo lo que el neoliberalismo nos quita...la utopía es sencilla poco académica, usa palabras simples para que todos y todas podamos entender que la utopía y las ganas de cambiar esta sociedad son nuestras, la utopía y las ganas de cambiar la sociedad se construyen, se crean, se reparten, se comparten.

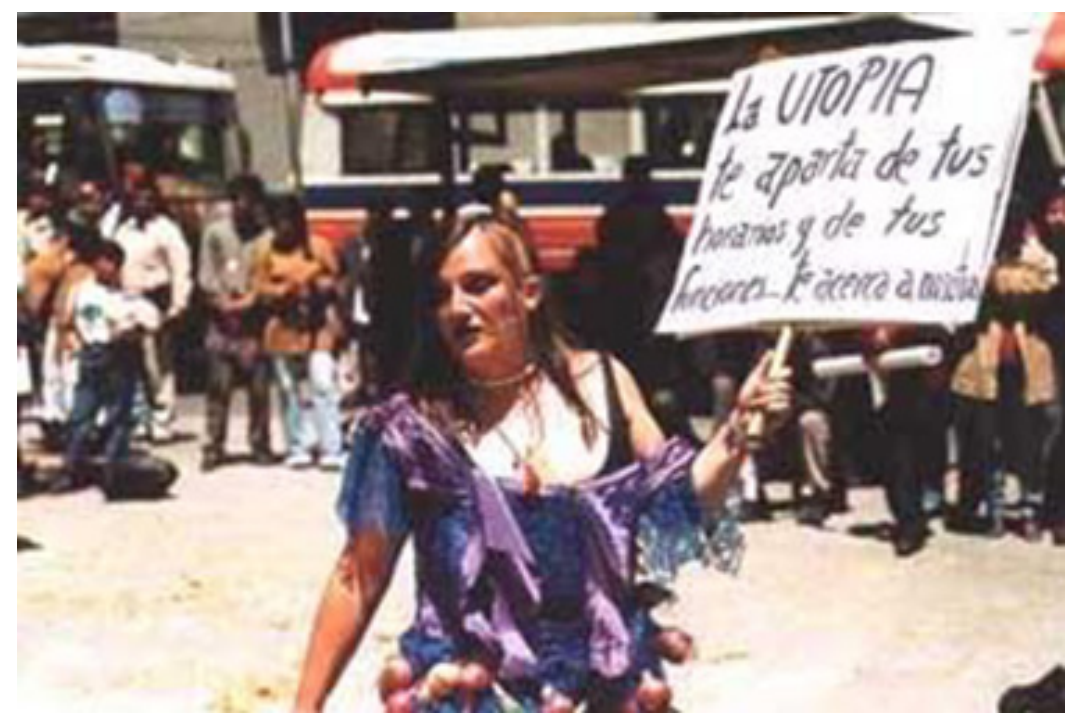

Figura 7. Mujeres Creando. Acción 2, 1992. Videoperformance, La Paz, Bolivia.

(Fuente: http://hemisphericinstitute.org/hemi/es/modules/itemlist/category/237-mujeres-works) 
Como expresa una de sus grafiteadas, "Utopía: cabalgadura que nos hace gigantas en miniatura", se trata de un concepto que forma parte de su teoría social y de su propuesta de vida, de manera que, acciones como esta convocan a soñar e inventar un mundo amoroso donde la comida se comparta, donde haya comida para todos y donde la mujeres no hayan de cargar con la mayor parte de la responsabilidad como consecuencia de la división sexual del trabajo y su vinculación al rol reproductivo.

Ahora bien, el camino de cómo solucionar la desigualdad y la injusticia social que encierran dichos problemas se abre hacia la comunidad activa. MC sabe sobradamente que cocinar y comer entrañan un gran universo simbólico, siendo prácticas de importante significación y producción de sentido en el interior de la comunidad. Por lo que esta acción recoge, en uno de sus niveles, la visibilización y re-existencia de prácticas comunitarias en las redes familiares, comunales, rituales, alimentarias, que han ido actualizándose en el tiempo debido a la colonialidad; y en otro, formas de vida otras que se oponen a la aceptación de las opresiones, al mito de la imposibilidad y a la pérdida de la memoria. Comer, dice A. Albán, es más que alimentarse: "Desde esta premisa, el acto de la ingesta de alimentos se constituye en un hecho cultural que va más allá de la nutrición, para convertirse en un complejo sistema de relaciones socioculturales, de cohesión de las comunidades y de conflictividad social” (Albán, 2010, p.15).

Este argumento hace su aparición en la acción a través de un personaje que entra en escena parodiando a una mujer blanca, burguesa, ataviada con un pomposo cuello de piel y guantes blancos en las manos. Irrumpe en la comida cuando todas las mujeres se encuentran sentadas a la mesa con las wawas y comienza a afearles la conducta, a recriminarles su manera de comer sin platos, así como la forma de enseñar a comer a los niños con las manos, "como animales". Las trata de locas y las conmina a levantar "esa basura", bajo la amenaza de llamar a la policía.

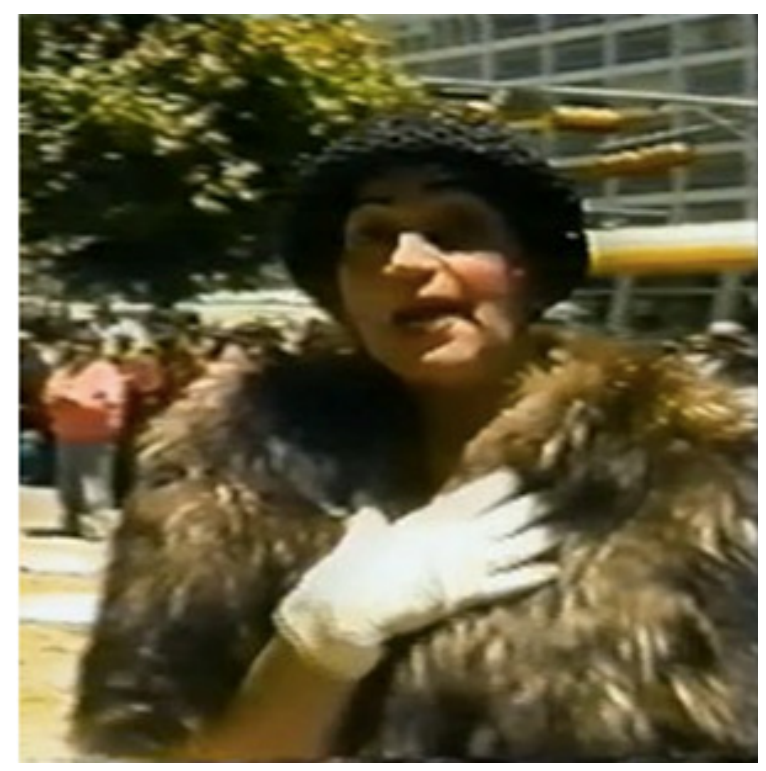

Figura 7. Mujeres Creando. Acción 2, 1992. Videoperformance, La Paz, Bolivia. 
Estos hechos podemos leerlos a la luz de las tesis de Adolfo Albán cuando explica cómo el colonialismo interno tuvo también un alcance gastronómico, puesto que, los modales, las normas de comportamiento y etiqueta en la mesa, los gustos e incluso los manuales de urbanidad y las recetas culinarias, no solo se importaron de Europa, sino que se impusieron a la fuerza, en detrimento de las maneras propias de comer. (Albán, 2010, p.17)

\begin{abstract}
No se escribieron manuales para ser buen campesino, buen indio, buen negro o buen gaucho, ya que todos estos tipos humanos eran vistos como pertenecientes al ámbito de la barbarie. Los manuales se escribieron para ser 'buen ciudadano'; para poder formar parte de la civitas, del espacio legal donde habitan los sujetos epistemológicos, morales y estéticos que necesita la modernidad. [...] El manual funciona dentro del campo de la autoridad desplegado por el libro con su intento de reglamentar la sujeción de los instintos, el control sobre los movimientos del cuerpo, la domesticación de todo tipo de sensibilidad considerada como 'bárbara'. La 'urbanidad' y la 'educación cívica' jugaron, entonces, con taxonomías pedagógicas que separaban el frac de la ruana, la pulcritud de la suciedad, la capital de las provincias, la república de las colonias, la civilización de la barbarie. (Castro-Gómez, 2010 [2005], pp. 158-159)
\end{abstract}

En esta senda, MC realiza una fuerte crítica a las mujeres blancas burguesas que en Bolivia mantienen una colonialidad cómplice con el patriarcado, al sostener un capital simbólico ético y estético racista y marginador, pues reproducen las relaciones de poder cuando asumen el rol de patrona, perfecta señorita, cúmulo de virtud, educación, belleza y limpieza, frente a la india, la chola, o la birlocha, considerándolas rudas, groseras y mugrientas. Grafiteadas como "Cholitas chotitas birlochas gringuitas y señoritas todas somos mujeres hermosas iBasta de racismos!" o "Que vivan las gordas que vivan las morenas todas somos modelos que imitar", evidencian también esta crítica.

El colonialismo interno ha generado, además, un imaginario estético, prejuicioso y discriminador, que ha lastimado cotidianamente los cuerpos, especialmente de las mujeres indígenas o de origen indígena. Este imaginario ético y estético de los cuerpos asigna criterios de belleza, educación y buen vestir. Califica por un lado como bonitas, educadas, limpias y bien vestidas a mujeres blancas o blanconas con rasgos occidentales. Califica por otro como las feas, maleducadas, sucias y mal vestidas a las mujeres morenas con rasgos indígenas. (Paredes, 2014 [2008], p.15)

Acción 8 sigue una lectura paralela. En ella, un grupo de mujeres se tumbaron boca abajo en el suelo de la calle formando un círculo, mientras soportaban sobre sus espaldas papas, verduras y grandes ollas, al tiempo que exhibían pancartas con consignas como, "mujer que se organiza no plancha más camisas", "las mujeres sostenemos este país", "no insista en este país no hay ni un solo empleo vacante", "pensar es altamente femenino", o "si te han crecido las ideas de ti van a decir cosas feas". En el centro del círculo, de pie, había unos personajes con máscaras grotescas que portaban carteles colgados al cuello con las palabras "patriarca", "jefe", "patrón", o "propietario". 




Figura 9. Mujeres Creando. Acción 2, 1992. Videoperformance, La Paz, Bolivia.

(Fuente: http://hidvl.nyu.edu/video/gf1vhkbf.html)

La simbología que representa tumbarse en el piso y apencar sobre las espaldas con los aperos de cocina o con los alimentos mientras pelan las papas, a la par que los patriarcas, jefes y patrones permanecen de pie de brazos cruzados, no se queda en la simple metáfora de las tareas mencionadas, sino que expresa un sentimiento de precariedad encarnado que resalta ese vínculo de explotación significado en las desigualdades globales grabadas en los cuerpos de las mujeres.

Al igual que veíamos en la acción anterior, se responde a la necesidad de tratar la cuestión del trabajo doméstico y de cuidados, que trasluce por sí misma la persistencia de los mecanismos de feminización y colonialidad del trabajo, que aún hoy continúan actualizándose mediante una serie de mecanismos de opresión, además del género, enraizados en las labores domésticas. Es decir, la cuestión se complejiza, pues las mujeres bolivianas indias y mestizas pobres, en tanto sujetos racializados, son utilizadas como materia prima, cuyo trabajo doméstico y de cuidado se considera como natural, no productivo, desvalorizado o construido como in-válido, al igual que quienes lo realizan. Por eso, las declaraciones de algunas de las mujeres participantes en la acción interpelan a los viandantes cuando dicen: "El trabajo no debería significar el sobrevivir, solamente trabajar para comer, sino también debería significar realizar tus sueños, realizar tus sueños, realizar tus fantasías, trabajar para ser feliz"; "basta de acoso en el trabajo, quiero un trabajo digno donde no me midan, no me acosen, un trabajo que respete mi cuerpo", o "yo quiero un trabajo en que no seamos pues como empleadas esclavas de las patronas, que las mujeres seamos libres y no sostener una carga a nuestras espaldas, nunca descansamos y sostenemos nuestro hogar y todo las mujeres de nuestro país".

En las acciones y manifiestos de MC se expresan y significan conocimientos, situaciones y lugares que la sociedad patriarcal menosprecia y considera intrascendentes, relegándolos a la 
clandestinidad y oscuridad de la "auténtica" vida social. Se ahonda en estos puntos ciegos al mostrar cómo el capitalismo avanzado sigue reproduciendo formas reminiscentes de explotación como son la esclavitud y la servidumbre laboral y sexual, atravesadas por esas relaciones patriarcales, pero también por la etnia y por la clase. Por otra parte, al situarse con sus cuerpos fuera de las estructuras de poder, al no pertenecer a la "esfera del arte", al producir "mal arte", al no ser "auténticas artistas", no solo desvelan las representaciones que reproducen y legitiman la matriz colonial, sino que las imágenes que generan a partir de la creatividad del ámbito doméstico, pasan de ser una herramienta de la dominación patriarcal-capitalista, a ser un desafío epistemológico y ontológico que demanda pensar otra visualidad que cree, sobre todo, sentidos en la comunidad. No en vano, al final de la acción, las mujeres son liberadas de esa carga, y los personajes se retiran las caretas, cambiando sus cartelas por otras donde aparece la palabra "hermano". Se trata de hombres que comienzan a lavar la ropa y a pelar papas, para terminar todos juntos escribiendo la palabra felicidad con patatas teñidas de rojo.

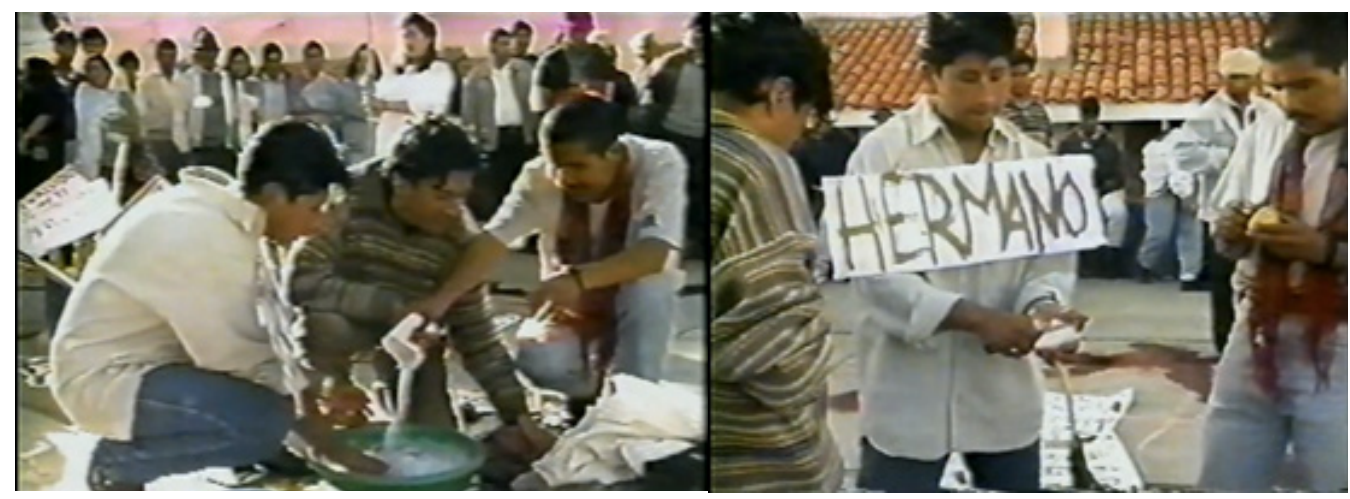

Figura 10. Mujeres Creando. Acción 2, 1992. Videoperformance, La Paz, Bolivia.

(Fuente: http://hidvl.nyu.edu/video/gf1vhkbf.html)

En este contexto, las acciones y grafiteadas de MC son, utilizando el término de Jesús MartinBarbero, veedurías (2001, p.49), formas actuales de fiscalización e intervención de la ciudadanía, llevadas a cabo, no mediante una relativización de la mirada, sino desde la exigencia de la complementariedad y reciprocidad visual. Por lo que, más que modos de representación, se trata de expresiones de participación que buscan confrontarse a otras miradas, interactuar con otros lugares dentro de la sociedad. "Lugares del ver y observar ciudadano, que, en su operación de control político del poder, permiten a su vez generar participación social, presencia activa en la vida pública" (Rey, 2003, pp. 4-9). 
Las mujeres bolivianas oprimidas desde la colonia han llevado a cabo prácticas y estrategias basadas en el lugar: el cuerpo, el hogar, el entorno local ambiental y la comunidad, en las condiciones específicas y concretas de sus vidas. Maniobras con las que han ido re-existiendo, es decir, "reelaborando la existencia" (Albán, 2010, p.22), a saber, reinventando sus formas de existencia a través de movimientos de emancipación, de la reinvención de sus identidades/ afinidades, de sus modos de ver y de pensar, de sus técnicas de producción y de sus medios de vida.

MC se suma a esta movida mediante una doble maniobra: por un lado, develando lo "visible in-visible", es decir las tareas de cuidado puestas a trabajar sin reconocimiento, que, aunque han sido veladas, pertenecen al "orden de la visibilidad", sacándolas a la calle, aireándolas en los medios de comunicación. Por otro, reivindicando "lo absolutamente no-visible"10, es decir, aquellos conocimientos y saberes que nunca son dados a la vista, como lo sonoro, lo gustativo, lo táctil, lo odorífero, para reactualizar la memoria de la experiencia como un todo indisoluble, en el que se funden los sentidos corporales y mentales. Prácticas basadas en la diferencia visual, cultural, ecológica y económica, desde donde producen imágenes alternativas. De manera que, maniobrar la visualidad supone para ellas un desafío descolonial ontológico y epistemológico inspirado en una memoria ancestral, que reinscribe lo político en lo cotidiano y crea sentidos de comunidad.

De donde resulta oportuno recordar la aserción de Nicholas Mirzoeff, cuando sostiene que "reclamar el derecho a mirar ha llegado a significar desplazarse más allá de una mirada oposicional hacia una autonomía basada en uno de sus primeros principios: el derecho a existir" $(2011$, p.4). Lo que nos hace caer en la cuenta de que rescatar el reconocimiento a través de la visualidad es siempre un acto político.

10 Jacques Derrida, en su obra Dar la muerte (2000), distingue entre lo "visible-invisible", que define como aquello que incluso sin estar "a la vista" pertenece al "orden de la visibilidad", es "constitutivamente visible", pero que "puedo mantener secreto sustrayéndolo a la vista"; y lo "absolutamente no-visible", es decir, todo lo que no se refiere al registro de la vista, que es invisible a esta. 


\section{Bibliografía}

Albán, A. (2013). Más allá de la razón hay un mundo de colores. Modernidades, colonialidades y re-existencia. Santiago de Cuba: Editorial Oriente.

Albán, A. (2010). Comida y colonialidad. Tensiones entre el proyecto hegemónico moderno y las memorias del paladar, Calle 14, 4(5), 10-23. Recuperado de http://revistas.udistrital.edu.co/ojs/ index.php/c14/article/view/1200/1586

Castro-Gómez, S. (2010 [2005]). La hybris del punto cero: ciencia, raza e ilustración en la Nueva Granada (1750-1816). Bogotá: Pontificia Universidad Javeriana.

Derrida, J. (2000). Dar la muerte. Barcelona: Paidós.

Escobar, A. (2003). Mundos y conocimientos de otro modo. El programa de investigación de modernidad/colonialidad latinoamericano, Tabula Rasa, 1, 51-56. Recuperado de http://www.revistatabularasa.org/numero-1/escobar.pdf

Escobar, A. (2010 [2008]). Territorios de la diferencia. Lugar, movimientos, vías, redes. Popoyán: Envión. Recuperado de http:// www.ram-wan.net/restrepo/documentos/Territorios.pdf

Escobar, A. y Harcourt, W. (2005). Las prácticas de la diferencia. En: Escobar, A. y Harcourt, W. (eds.) Las mujeres y las políticas del lugar. México D.F.: PUEG-UNAM.

Galindo, M. (2005). La virgen de los deseos. Buenos Aires: Tinta Limón.

Galindo, M. y Paredes, J. (1999). Grafiteadas. La Paz: Mujeres Creando.

González Casanova, P. (2003). Colonialismo interno (una redefinición). Revista Rebeldía, 12. Recuperado de http://www.revistarebeldia.org/revistas/012/art06.html

Guzmán, A. y Paredes, J. (2014). El tejido de la rebeldía. ¿Qué es el feminismo comunitario? Bases para la Despatriarcalización. La Paz: Mujeres Creando Comunidad.

Martín-Barbero, J. (2001). Transformaciones comunicativas y tecnologías de lo público, Metapolítica, 5(17), 46-55. Recuperado de 
https://es.scribd.com/doc/7405406/Transformaciones-tecnologicas-y-comunicativas-de-lo-publico

Martínez, R. et al. (2018). Cuidado, comunidad y común. Extracciones, apropiaciones y sostenimiento de la vida. Madrid: Traficantes de sueños.

Mirzoeff, N. (2011). The Right to Look. Chicago: The University of Chicago Press.

Paredes, J. (2013). Disidencia y feminismo comunitario. Emisférica, 10(2). Recuperado de https://hemisphericinstitute.org/en/ emisferica-102/10-2-dossier/disidencia-y-feminismo-comunitario.html

Paredes, J. (2014 [2008]). Hilando fino. La Paz: Comunidad Mujeres Creando Comunidad.

Precarias a la deriva (2005). Una huelga de mucho cuidado, Transversal. Recuperado de http://eipcp.net/transversal/0704/precarias $2 /$ es

Rey, G. (2003). Ver desde la ciudadanía. Observatorios y veedurías de medios de comunicación en América Latina, Centro de competencia en Comunicación para América Latina, Recuperado de http://library.fes.de/pdf-files/bueros/kolumbien/04198.pdf

Rivera, S. (2010). Violencias (re) encubiertas en Bolivia. La Paz: Piedra rota.

Sandoval, C. (2000). Metodology of Opressed. Minneapolis/ London: Theory out of bounds.

Sandoval, C. (2004 [1995]). Nuevas ciencias. Feminismo cyborg y metodología de los oprimidos". En: Otras inapropiables. Feminismos desde las fronteras. Madrid: Traficantes de sueños.

Santos, B. (2006). Conocer desde el Sur. Para una cultura política empancipatoria. Lima: UNMSM/Programa de Estudios sobre Democracia y Transformación Global.

Taylor, D. (2011). Introducción, Performance, teoría y práctica. En: Fuentes, M. \& Taylor, S. (eds.). Estudios avanzados de performance. México D.F.: Fondo de Cultura Económica. 